\title{
ERRATUM
}

Mark Mackiewicz $\cdot$ Brady A. Porter

Elizabeth E. Dakin · John C. Avise

\section{Cuckoldry rates in the Molly Miller (Scartella cristata; Blenniidae), a hole-nesting marine fish with alternative reproductive tactics}

Published online: 19 August 2005

(C) Springer-Verlag 2005

\section{Marine Biology DOI 10.1007/s00227-005-0010-9}

Owing to technical problems, only the online pdf version of this article includes the author's proof corrections. Please consult the online pdf article for the final version.

In both online and print versions, Fig. 3 appears twice, as Fig. 2 and as Fig. 3. The correct Fig. 2 is shown below.

The online version of the original article can be found at http:// dx.doi.org/10.1007/s00227-005-0010-9

M. Mackiewicz $(\bowtie) \cdot$ E. E. Dakin · J. C. Avise Department of Genetics,

University of Georgia, Athens, GA 30602, USA

E-mail:mmack@uga.edu

Fax: + 1-706-5830359

B. A. Porter

Department of Biological Sciences, Duquesne University, Pittsburgh, PA 15282, USA 


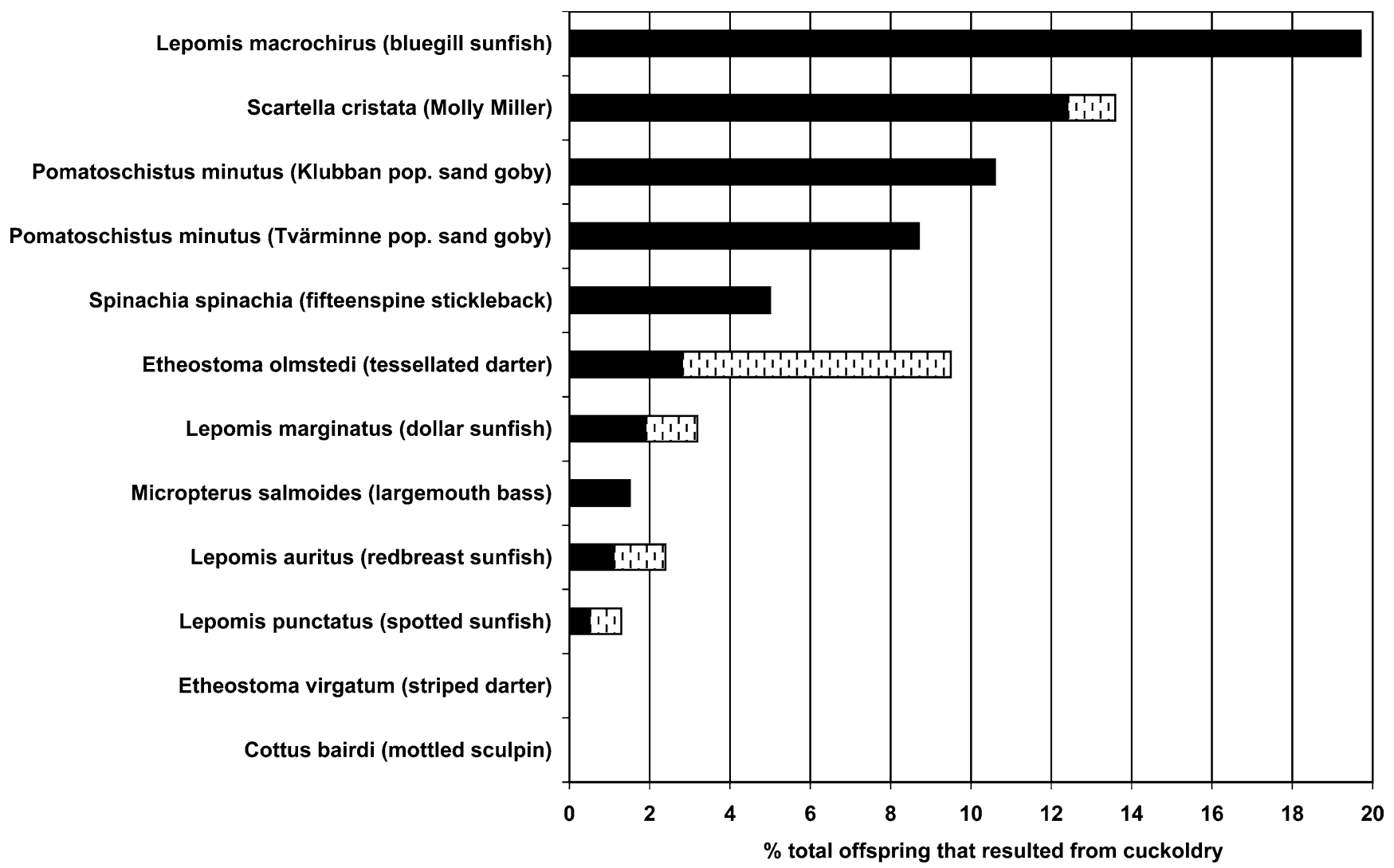

Fig. 2 Microsatellite-deduced cuckoldry rates (total percentages of progeny arising from sneaked fertilizations in a given population) gleaned from previous reports on fish species with male nest-tenders (DeWoody et al. 1998, 2000a, b, c; Fiumera et al. 2002; Jones et al. 1998, 2001a, b; Mackiewicz et al. 2002; Neff 2001; Porter et al. 2002). Black bars are minimum estimates of cuckoldry rates in the sense that fertilizations were deemed to be sneaked only if the relevant progeny had guardian-inconsistent alleles at two or more loci. Gray bars indicate the higher such estimates when single-locus guardian-inconsistent alleles are provisionally interpreted to indicate sneaked fertilization events as well (rather than de novo mutations in the bourgeois male's germ line). Probable nest-takeover events (as evidenced by all or nearly all progeny within a nest being foster embryos to their guardian) were not counted as cuckoldry events via sneaking in the estimates summarized here 